\title{
RADIATION SENSITIVITY OF BACTERIA CONTAMINATING FOOD
}

\section{Anna Suponkina ${ }^{*}$, Michael Zhukovsky², Anna Krivonogova ${ }^{3}$, Kseniya Shcherbakova', Kseniya Moiseeva ${ }^{3}$}

\author{
${ }^{1}$ Ural Federal University, Ekaterinburg, Russia \\ 2Institute of Industrial Ecology UB RUS, Ekaterinburg, Russia \\ 3Ural State Agricultural University, Ekaterinburg, Russia
}

\begin{abstract}
Pulsed accelerators with high doses per pulse are currently widely used. The effects of this irradiation on microorganisms are poorly understood. The objectives of our study are: 1) the development of methods to study the effects of pulsed electron beams on microorganisms; 2) the preliminary study of radiation resistance of microorganisms interesting in the context of food safety. In this study, irradiation was conducted on two pulsed accelerators: URT-1 and URT-O.5. Experiments on the dose distribution in the layer of $80 \mathrm{mg} / \mathrm{cm}^{2}$ at URT-O.5 and URT-1 showed that the penetration of radiation at URT-1 is greater than at URT-O.5. So, for our experiments, URT-1 is more suitable than URT-0.5.We investigated the effects of pulsed electron beams on the survival of bacterial (Klebsiella, Citrobacter, Staphylococcus aureus, Salmonella) and fungal (Aspergillus) food spoilage agents. The results for Staphylococcus aureus, Salmonella, fungus Aspergillus are similar. 6kGy is the dose at which the survival is reduced by 40-50\%, $11 \mathrm{kGy}$ is the dose at which the survival is reduced by 90-100\% (11 kGy is upper limit of radappertization). The inactivation of bacteria on the accelerator URT-1 occurred at lower doses compared with the accelerator URT-0.5.
\end{abstract}

Key words: Bacterial inactivation, electron irradiation, nanosecond pulses

DOI: 10.21175/RadProc.2016.01

\section{INTRODUCTION}

Radiation processing of food products is carried out in order to improve their safety and quality. Food irradiation is used to inactivate pathogens and parasites, for reducing the number of microorganisms that cause food spoilage, for suppressing sprouting bulbs, tubers and roots, for extending the shelf life of products, as well as for the phytosanitary treatment.

To sterilize food, International Atomic Energy Agency (IAEA) special terms are offered:

radicidation (4-6 kGy) -radiation treatment to selectively suppress a specific type of microorganism (e.g., Salmonella);

radurization (6-10 $\mathrm{kGy})$ - radiation processing of food products in order to increase storage duration, in doses that lead to the suppression of limited humanpathogenic microorganisms;

radappertization (10-50 kGy) - carried out for industrial sterilization of foods under conditions precluding the repetition of infection by microorganisms

Currently, the radiation processing of food products involves the following types of ionizing radiation:

1. electron beam with energy up to $10 \mathrm{MeV}$;

2. $\gamma$-radiation radioisotope ${ }^{60} \mathrm{Co}\left(\mathrm{T}_{1 / 2}=5.27\right.$ years, $\mathrm{E}=$ $1.25 \mathrm{MeV}$ );

\footnotetext{
*anna.suponkina@rambler.ru
}

3. $\gamma$-radiation radioisotope ${ }^{137} \mathrm{Cs}\left(\mathrm{T}_{1 / 2}=30.17\right.$ years, $\mathrm{E}=$ $0.66 \mathrm{MeV}$ );

4. bremsstrahlung generated by electron accelerators with energies up to $5 \mathrm{MeV}$ [1].

The objectives of this study are:

1) development of methods to assess the effects of pulsed electron beams on microorganisms;

2) preliminary study of radiation resistance of microorganisms of interesting in the context of food safety.

The following microorganisms were used as biological models:

a) Klebsiella is opportunistic pathogens belonging to the Enterobacteriaceae found in human feces, skin and mucous membranes of the respiratory tract, soil, water, fruits and vegetables;

b) Citrobacter belonging to the Enterobacteriaceae family, commonly found in the human intestinal microbiota. Pathogenic species are occasionally implicated in food poisoning mainly associated with milk and dairy products, pastries, poultry and meat;

c) Salmonellais also a member of the Enterobacteriaceae family that occurs in the human intestine. Pathogenic species can be transmitted by contaminated food, especially eggs, dairy products, poultry and meat;

d) Staphylococcus aureus are Gram positive opportunistic pathogens. Although commonly 
occurring in the human skin and oral mucosa, $\mathrm{S}$. aureus is an agent of food intoxication mainly associated to the consumption of milk and dairy products, pastries and ready-to-eat food;

e) Aspergillus is a genus of filamentous fungi (molds) that includes several hundred species widely distributed in the environment. Some Aspergillus species cause serious diseases in humans and animals. Some pathogenic species like $A$. fumigatus and $A$. flavus, produce aflatoxins which are powerful carcinogens. Aspergillus can contaminate food with low water content, such as nuts, seeds and grains [2].

Some previous studies have addressed the effects of electron irradiation on these types of bacteria. For example, at doses up to $2.5 \mathrm{kGy}$ survival of Salmonella typhi decreases by $99 \%$ under the influence of electron irradiation from a linear accelerator with an energy of $6 \mathrm{MeV}$ [3]. Survival of Staphylococcus intermedius decreases by $99 \%$ at doses up to $5 \mathrm{kGy}$ [3]. Under the influence of electron irradiation survival of fungus Aspergillius decreases by $90 \%$ at doses up to $0.2 \mathrm{kGy}$ [4].

\section{IRRADIATION AND DOSIMETRY}

Irradiation was conducted on two pulsed accelerators, URT-1 and URT-0.5, at the Institute of Electrophysics, the Ural Branch of the Russian Academy of Sciences. Characteristics of the accelerators are shown in Table 1.

Table 1. Characteristics of the accelerators URT-0.5 and URT-1

\begin{tabular}{|l|l|l|}
\hline Characteristics & URT-0,5 & URT-1 \\
\hline the accelerating voltage, keV & 500 & 650 \\
\hline $\begin{array}{l}\text { the pulse width at half-maximum, } \\
\text { ns }\end{array}$ & 50 & 60 \\
\hline frequency, $\mathrm{Hz}$ & 200 & 50 \\
\hline $\begin{array}{l}\text { beam size, } \mathrm{mm}^{2} \text { / beam diameter, } \\
\mathrm{mm}\end{array}$ & $120 \times 120$ & 160 \\
\hline beam current density, A / cm ${ }^{2}$ & 10 & 2 \\
\hline $\begin{array}{l}\text { the average dose per pulse, } \mathrm{kGy} / \\
\text { imp. }\end{array}$ & 0,8 & 1,8 \\
\hline
\end{tabular}

Doses were measured with film dosimeters $\operatorname{SOPD}(\mathrm{F}) \mathrm{R}-5 / 50$ and $\operatorname{SOPD}(\mathrm{E})-1 / 10$. The dosimeters are polymer films of single use. They are designed to measure the absorbed dose of photon and electron radiation (copolymer with phenazine dye SOPD(F)R - 5/50 and copolymer with 4 dietilaminobenzolovym dye - SOPD(E) - 1/10) The optical density of the film changes during the radiation exposure. We measured the optical density with a spectrophotometer. We determined the absorbed dose using the following formula (1), (2). The formula for dosimeters $\operatorname{COPD}(\mathrm{F}) \mathrm{R}-5 / 50$ is:

$$
D=59,71 \cdot A^{1,02},
$$

where $\mathrm{D}$ is the absorbed dose of electron radiation in the range of $5-50 \mathrm{kGy}$; $\mathrm{A}$ is the optical density measured by a spectrophotometer at a wavelength of $\lambda$ $=512 \mathrm{~nm}$, relative to a reference sample.

The error in determining the absorbed dose using COPD $(\mathrm{F}) \mathrm{R}-5 / 50$ does not exceed $12 \%(\mathrm{P}=0.95)$ in the working conditions of use.
The formula for dosimeters $\operatorname{SOPD}(\mathrm{E})-1 / 10$ is:

$$
D=8,78 \cdot A^{0,924} \text {, }
$$

where $\mathrm{D}$ is the absorbed dose of electron radiation in the range of 1 - $10 \mathrm{kGy}$; A is the optical density measured in a spectrophotometer at a wavelength of $\lambda$ $=550 \mathrm{~nm}$, relative to a reference sample.

The error in determining the absorbed dose using $\mathrm{SOPD}(\mathrm{E})-1 / 1$ odoes not exceed $15 \%(\mathrm{P}=0.95)$ in the working conditions of use.

Accelerators URT-0.5 and URT-1 are not directly suitable for radiobiological research. Therefore, some radiation field characteristics were namely: depth dose distribution and area. Irradiation was carried out in a Petri dish and in a plastic bag. As the simulator of biological tissue, we used polyethylene films. Film dosimeters were places between absorber layers. The dose distribution in depth obtained with accelerator URT-0.5 is represented in Figure 1 . The dose distribution in depth with accelerator URT-1 is represented in Figure 2.

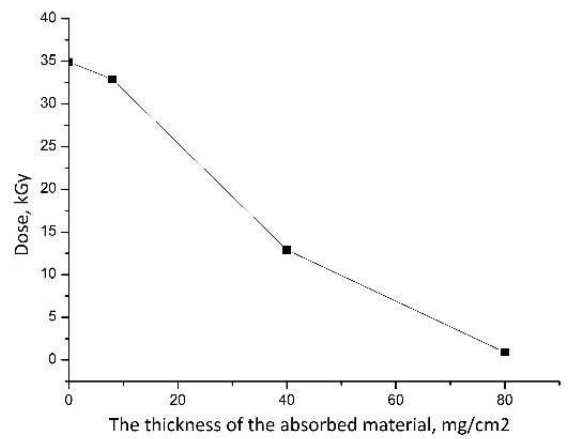

Figure 1. Dose distribution in depth with accelerator URT-0.5

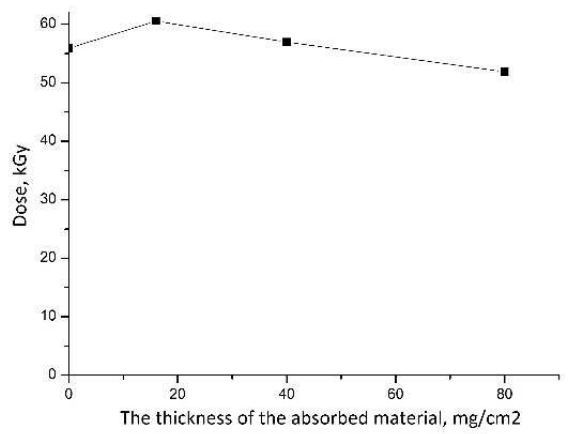

Figure 2. Dose distribution in-depth with accelerator URT-1

A significant decline in the dose was observed with accelerator URT-0.5. Therefore, this accelerator was found for the irradiation of very thin samples. With accelerator URT-1, the dose depth varies only slightly. Consequently, the accelerator URT-1 is more suitable for the use in radiobiological experiments.

Microorganism suspension before irradiation was prepared in a liquid nutrient medium. Then these suspensions were deposited on solid culture medium 
in Petri dishes and were irradiated. Klebsiella and Citrobacter were irradiated in the accelerator URT-0.5. We adjusted the dose by changing the number of pulses. The width and pulse frequency were not changed. Irradiation was carried out at the following doses: 5 kGy (8 pulses); 10 kGy (16 pulses); 15 kGy (23 pulses); 20 kGy (31 pulses); 25 kGy (39 pulses); 30 $\mathrm{kGy}(47$ pulses).The plates are placed in an incubator. After 48 hours of incubation, the survival of the bacteria was estimated by counting colony forming units (CFU) per ml. The surviving fraction corresponding to each dose was determined by dividing the number of colonies in irradiated sample on the number of colonies in control sample. Control samples were kept in the same conditions as the other samples, but were not subjected to irradiation. Values of surviving fractions were calculated and approximated by Boltzmann sigmoidal function (3) with two fixed parameters $A_{2}=0$ and $A_{1}=1$

$$
f(x)=\left(\frac{\left(A_{1}+A_{2}\right)}{1+e^{\left(\frac{x-x_{0}}{d x}\right)}}\right)+A_{2} .
$$

Here, $\mathrm{X}_{0}=\mathrm{LD} 50$ (the dose at which survival corresponds to $50 \%$ ) and $\mathrm{dx}=$ width of the transition from the survival fraction 1 to fraction $=0$ survival.

The results of these experiments are shown in Figure 3.

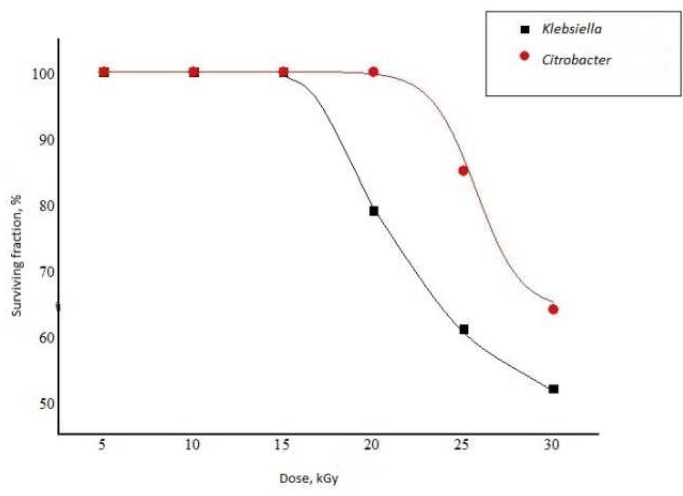

Figure 3. Survival of Klebsiella ( $\bullet$ ) and Citrobacter $(\bullet)$ after irradiation with the electron beam accelerator URT-0.5

The LD50, determined by the point values, was 30 kGy for Klebsiellaand35 kGy for Citrobacter.

The thickness of the samples was approximately 80 $\mathrm{mg} / \mathrm{cm}^{2}$. The dose varies considerably for a given value of the sample thickness on the accelerator-URT 0.5. Therefore, it is likely that the heterogeneity of radiation in depth could affect bacterial survival.

Salmonella, Staphylococcus and Aspergillus were irradiated on the accelerator URT-1. The width and pulse frequency were not changed. We adjusted the dose by changing the number of pulses. Irradiation was carried out at the following doses: $6 \mathrm{kGy}$ (4 pulses); 11 kGy (10 pulses); 15 kGy (22 pulses). Experimental results are presented in Table 2.

At the dose of $6 \mathrm{kGy}$, the survival of Staphylococcus decreased by $40 \%$. The dose at which total inactivation occurred was $11 \mathrm{kGy}$.

At the dose of $6 \mathrm{kGy}$, the survival of Salmonella decreased by $40 \%$, whereas the survival at the dose of
$11 \mathrm{kGy}$ decreased by $95 \%$. In addition, the cell colonies changed their shape and color.

We studied the effect of radiation on the hyphae of the fungus Aspergillus. The survival of hyphae decreased by $49 \%$ at the dose of $6 \mathrm{kGy}$. The dose at which total inactivation occurred was $11 \mathrm{kGy}$.

The death of the bacteria on the accelerator URT-1 occurred at lower doses compared with the accelerator URT-0.5.

Table 2. Survival of the bacteria after irradiation on the accelerator URT-1 (CFU/mL)

\begin{tabular}{|l|c|c|c|}
\hline \multicolumn{1}{|c|}{ Test/Control } & \multicolumn{3}{c|}{ Dose, kGy } \\
\hline & 6 & 11 & 15 \\
\hline S. aureus & 300 & - & - \\
\hline control & \multicolumn{3}{|c|}{500} \\
\hline Salmonella & 300 & 27 & - \\
\hline control & \multicolumn{4}{|c|}{500} \\
\hline Aspergillus & 51 & - & - \\
\hline control & \multicolumn{4}{|c|}{100} \\
\hline
\end{tabular}

\section{CONCLUSION}

Experiments on the dose distribution in the layer of $80 \mathrm{mg} / \mathrm{cm}^{2}$ at URT-0.5 and URT-1 showed that the penetrating ability of radiation at URT- 1 is greater than at URT-0.5. Therefore, the accelerator URT-1 is more suitable for the use in radiobiological experiments.

We investigated how nanosecond electron beams affect the survival of the bacteria contaminating food (Klebsiella, Citrobacter, Staphylococcus aureus, Salmonella, fungus Aspergillus).

Citrobacter and Klebsiella cultures were exposed to $500 \mathrm{keV}$ electrons at an average dose ofo.8kGy/pulse, with a repetition rate of 200 pulses per second, with a pulse width of 50 ns. The LD50, determined by the point values, was $30 \mathrm{kGy}$ for Klebsiella and $35 \mathrm{kGy}$ for Citrobacter. Experiments showed that Klebsiellais more susceptible to nanosecond electron beams than Citrobacter. On the accelerator URT-0.5, the dose varies considerably at a sample thickness of 80 $\mathrm{mg} / \mathrm{cm}^{2}$. Therefore, it is likely that the heterogeneity of radiation in depth could affect the survival of the bacteria. Thus, we got the bacterial survival for specific experimental conditions. These results cannot be the characteristic of radiosensitivity of these bacteria.

Staphylococcus, Salmonella and Aspergillus cultures were irradiated with $650 \mathrm{keV}$ electrons, at an average dose of $1.8 \mathrm{kGy} /$ pulse with a repetition rate of 50 pulses per second, with a pulse width of $60 \mathrm{~ns}$. We found that the survival of Staphylococcus decreased by $40 \%$ at the dose of $6 \mathrm{kGy}$. The dose limit at which all the bacteria were destroyed was $11 \mathrm{kGy}$. The survival of Salmonella decreased by $40 \%$ at the dose of $6 \mathrm{kGy}$, whereas the survival of Salmonella decreased by $95 \%$ at the dose of $11 \mathrm{kGy}$. In addition, the cell colonies changed their shape and color. The survival of Aspergillus decreased by $49 \%$ at the dose of $6 \mathrm{kGy}$, and fungal hyphae were completely destroyed at the dose of $11 \mathrm{kGy}$.

The results for the two types of bacteria and fungi are similar.6kGy is the dose at which the survival is reduced by $40-50 \%$, and $11 \mathrm{kGy}$ is the dose at which the 
survival is reduced by $90-100 \%$ ( $11 \mathrm{kGy}$ is the upper limit for radappertization). The death of the bacteria on the accelerator URT-1 occurred at lower doses compared with the accelerator URT-0.5.

Based on these results, we can conclude that the accelerator URT-1 is optimal for radiobiological studies. All subsequent experiments are planned to be carried out on it. Further, it is necessary to examine how the survival of Staphylococcus, Salmonella and Aspergillus will change at doses up to $11 \mathrm{kGy}$. In addition, we plan to conduct experiments with the same kinds of bacteria in the linear electron accelerator with the energy of $10 \mathrm{MeV}$. The preliminary dosimetry for these purposes has already been carried out.

\section{REFERENCES}

1.Т.В. Чиж, Г.В. Козьмин, Л.П. Полякова и Т.В. Мельникова, „Радиационная обработка как технологический прием в целях повышения уровня продовольственной безопасности,“ Вестн. Росс.. акад ест. наук, № 4, с. 44-49, 2011. (T.V. Chizh, G.V. Kozmin, L.P. Polyakova and T.V. Melnikova, "Radiation Treatment as a Technological Method in order to Improve Food Security," Herald Russ. Acad. Natur. Sci., no. 4, pp. 44-49, 2011)
2.А.А. Воробьев и А.С. Быков, Атлас по медицинской микробиологии, вирусологии и иммунологии, Москва, Россия: Мед. инф. агентство, 2003. (А.А. Vorobiev and A.S. Bykov, Atlas of Medical Microbiology, Virusology and Immunology, Moscow: Med. Inf. Agency, 2003)

3.D.I. Martin et al., "Application of Accelerated Electron Beam and Microwave Irradiation to Biological Waste Treatment," Vacuum, vol. 77, no. 11, pp. 501-506, Mar. 2005

4.G. Blank and D. Corrigan, "Comparison of Resistance of Fungal Spores to Gamma and Electron Beam Radiation," Int. J. Food Microbiol., vol. 26, no. 3, pp. 269-277, Aug. 1995 